\title{
Comparison of mid-term outcomes of endovascular repair and medical management in patients with acute uncomplicated type B aortic dissection
}

\author{
Dongqiao Xiang, MS, Xuefeng Kan, MD, Huimin Liang, MD, Bin Xiong, MD, Bin Liang, MD, \\ Lixia Wang, MD, and Chuansheng Zheng, MD
}

\section{ABSTRACT}

Objectives: To further assess the early and mid-term outcomes of thoracic endovascular aortic repair (TEVAR) in patients with acute uncomplicated type B aortic dissection (TBAD) compared with those receiving best medical treatment (BMT).

Methods: Between February 2008 and March 2018, 357 consecutive patients with acute uncomplicated TBAD were retrospectively analyzed. Among them, 191 patients underwent TEVAR, and 166 received BMT. After propensity score matching, we obtained 145 matched pairs for analysis.

Results: In the matched population, the 30-day mortality between the TEVAR group and the BMT group showed no statistically significant difference, whereas the early adverse events rates in the TEVAR group were significantly greater than that of the BMT group $(P=.003)$. Freedom from all-cause mortality in the TEVAR group was significantly greater than that of the BMT group (TEVAR: $91.9 \%$ at 5 years, BMT: $82.2 \%$ at 5 years, $P=.028)$. Freedom from aortic-related mortality in the TEVAR group was significantly greater than that of the BMT group (TEVAR: $94.1 \%$ at 5 years, BMT: $86.1 \%$ at 5 years, $P=.044)$. Multivariable Cox-hazard regression analysis demonstrated that the older age (hazard ratio [HR], 1.04; 95\% confidence interval $[\mathrm{Cl}], 1.01-1.08, P=.013)$, BMT (HR, 2.33; 95\% Cl, 1.08-5.05, $P=.032)$, and the distance between the primary entry tear and the left subclavian artery $<2.0 \mathrm{~cm}(\mathrm{HR}$, 2.30; $95 \% \mathrm{Cl}, 1.06-4.99, P=.035)$ were the significant risk factors for all-cause death. Given death as a competing factor, the cumulative incidence of rupture in the BMT group was significantly greater than that of the TEVAR group (BMT: $13.7 \%$ at 5 years, TEVAR: $5.1 \%$ at 5 years, $P=.024$ ).

Conclusions: Despite more complications in the early stage, TEVAR was associated with decreased risk of late death and had fewer late aortic ruptures compared with BMT in patients with acute uncomplicated TBAD. Therefore, TEVAR may be considered as the first option to improve the late outcomes in these patients. (J Thorac Cardiovasc Surg 2021;162:26-36)

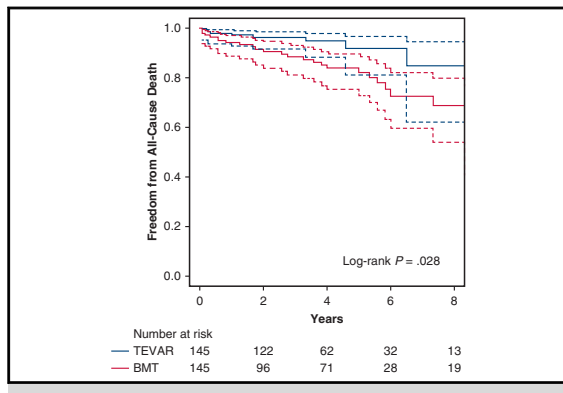

Freedom from all-cause death between the TEVAR and BMT groups.

CENTRAL MESSAGE

TEVAR was associated with a better mid-term survival and

fewer late aortic ruptures compared with BMT in patients with acute uncomplicated TBAD. TEVAR may be considered the first option.

\section{PERSPECTIVE \\ This large-sample retrospective study suggested that TEVAR was associated with a lower rate of late aortic ruptures and late mortality compared with BMT in patients with acute uncomplicated TBAD. Randomized controlled trials are needed to compare the mid- and long-term outcomes of TEVAR with BMT in these patients.}

See Commentaries on pages 37 and 38 .
Acute type B aortic dissection (TBAD) is a life-threatening condition with characteristics of sudden onset, rapid progression, and high mortality. ${ }^{1,2}$ Benefiting from the lower

From the Department of Radiology, Union Hospital, Tongji Medical College, Huazhong University of Science and Technology; and Hubei Province Key Laboratory of Molecular Imaging, Wuhan, China.

D. Xiang and X. Kan contributed equally as co-first authors. L. Wang and C. Zheng contributed equally as co-corresponding authors.

Received for publication July 8, 2019; revisions received Nov 18, 2019; accepted for publication Nov 28, 2019; available ahead of print Dec 24, 2019.

Address for reprints: Lixia Wang, MD, or Chuansheng Zheng, MD, Department of Radiology, Union Hospital, Tongji Medical College, Huazhong University of Sci- perioperative mortality than open surgery, thoracic endovascular aortic repair (TEVAR) has become the treatment of choice for acute complicated TBAD. ${ }^{3,4}$ Traditionally,

ence and Technology, Wuhan 430022, China (E-mail: lisa2003627@163.com or hqzcsxh@sina.com). 0022-5223

Copyright $(2019$ by The American Association for Thoracic Surgery. Published by Elsevier Inc. This is an open access article under the CC BY-NC-ND license (http:// creativecommons.org/licenses/by-nc-nd/4.0/).

https://doi.org/10.1016/j.jtcvs.2019.11.127 

Abbreviations and Acronyms
$\mathrm{A}-\mathrm{AD}=$ type $\mathrm{A}$ aortic dissection
BMT $=$ best medical treatment
CI = confidence interval
CTA = computed tomography angiography
$\mathrm{HR}=$ hazard ratio
LCCA $=$ left common carotid artery
LSA $=$ left subclavian artery
PSM = propensity score matching
$\mathrm{SBP}=$ systolic blood pressure
TBAD $=$ type $\mathrm{B}$ aortic dissection
TEVAR $=$ thoracic endovascular aortic repair

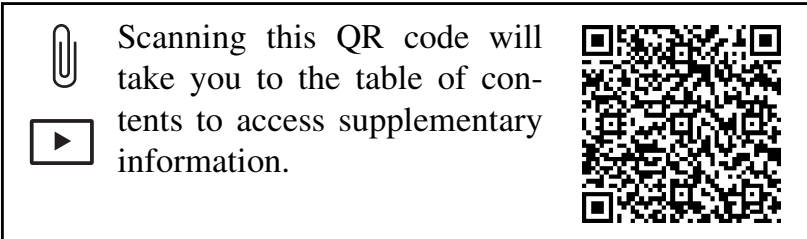

patients with uncomplicated TBAD are treated conservatively by controlling hypertension and close monitoring; in other words, the best medical treatment (BMT). ${ }^{5}$ However, the long-term outcomes of BMT in patients with uncomplicated TBAD are less than satisfactory, with a reported $30 \%$ to $50 \%$ cumulative mortality at 5 years and a $20 \%$ to $50 \%$ delayed false-lumen expansion at 4 years. ${ }^{6-8}$

TEVAR has the advantage of stabilizing a dissected aorta, inducing aortic remodeling processes, and promoting false lumen thrombosis. ${ }^{4}$ A thrombosed false lumen is associated with improved survival and reduced late adverse events of acute TBAD. ${ }^{9}$ Given this fact, preemptive TEVAR has also been performed in patients with acute uncomplicated TBAD to reduce late morbidity and mortality. ${ }^{9-12}$ Recently, a few published studies have compared the early and late outcomes of TEVAR with BMT in patients with acute uncomplicated TBAD. ${ }^{9-13}$ However, the majority of these studies have been based on limited numbers of patients and/or short follow-up period ${ }^{10,14-17}$ and did not reach consistent conclusions regarding the early and late outcomes of TEVAR in patients with acute uncomplicated TBAD. The purpose of this retrospective study was to further assess the early and mid-term outcomes of TEVAR in patients with acute uncomplicated TBAD compared with those receiving BMT.

\section{PATIENTS AND METHODS Study Population}

Between February 2008 and March 2018, all patients with acute uncomplicated TBAD were retrospectively obtained from medical records of the Union Hospital of Huazhong University of Science and Technology. Aortic dissection was classified as type B following the Stanford classification.
Acute aortic dissection was considered if patients received treatment within 14 days of initial symptom onset. Acute uncomplicated TBAD is defined as dissection without rupture, malperfusion syndromes, refractory pain, or rapid aortic expansion at the onset or during presentation at the hospital. ${ }^{18}$ Patients meeting the following criteria were excluded: were younger than 18 years; had aortic dissection secondary to trauma, iatrogenic injury, or intramural hematoma; or had Marfan syndrome or Ehlers-Danlos syndrome. A flow chart of study population is shown in Figure 1. For the present report, the follow-up period was closed on December 30, 2018. Computed tomography angiography (CTA) examinations of the aorta were routinely performed within 30 days of the TEVAR procedure for the TEVAR group, at 3,6, and 12 months and yearly thereafter for all qualified patients. A total of 12 patients were lost to follow-up during the study period. Follow-up completeness rate was $95.9 \%$. The median (interquartile range) follow-up duration was 3.2 (1.9-4.2) years in the TEVAR group and 3.8 (1.3-5.6) in the BMT group. The local ethical review board approved this study, and the informed consent was waived for this retrospective study.

Information about the baseline patient characteristics and details of medical and endovascular management were collected from the electronic medical record database of the hospital and outpatient clinic notes. The initial diagnostic and follow-up CTA and digital subtraction angiography images were retrieved from the hospital's imaging archiving system. The anatomic characteristics, the extent of the dissection (using the orifice of the celiac trunk as a divide of the thoracic and abdominal aorta), the thrombosis status of the false lumen, and postoperative aortic-related complications were evaluated retrospectively and documented by 2 experienced radiologists. The final survival state was determined by reviewing hospital admitting notes or death certificate issued by other hospitals.

Patients were divided into 2 groups according to their therapeutic regimen. The TEVAR group consisted of patients with acute uncomplicated TBAD who were treated with TEVAR in addition to medical therapy. The BMT group was made up of patients with acute uncomplicated TBAD who received only medical therapy.

\section{Medical Management}

The primary aim of medical therapy was to reduce shear stress on the diseased segment of the aorta by reducing blood pressure and cardiac contractility. ${ }^{4}$ All patients with systolic blood pressure (SBP) $>120 \mathrm{~mm}$ $\mathrm{Hg}$ received active antihypertensive therapy, regardless of the group assignment. Antihypertensive treatment with intravenous beta-blocking agents, nitroglycerin, and calcium-channel blockers was initiated to lower the SBP to between 100 and $120 \mathrm{~mm} \mathrm{Hg}$ and reduce the heart rate. In patients with refractory hypertension, a combination of several antihypertensives was administered. Pain symptoms in patients with acute uncomplicated TBAD were usually relieved after antihypertensive therapy; if necessary, in our treatment procedure, a narcotic analgesic (morphine hydrochloride) was administered, regardless of the group assignment. After discharge, SBP should be regulated to below $140 \mathrm{~mm} \mathrm{Hg}$ with lifestyle changes and adequate use of antihypertensive drugs.

\section{TEVAR Procedure}

The decision to perform TEVAR in patients with acute uncomplicated TBAD was usually made by the patient and their families based on a full understanding of the advantages and disadvantages of various therapeutic regimens. In brief, the stent-graft procedures were performed in an angiography suite. A 5-French calibrated angiographic pigtail catheter was advanced into the ascending aorta to permit an arteriographic evaluation of the distance between the left subclavian artery (LSA) and the entry tear and the diameter of the aorta where the stent-graft will be implanted. The length of the stent-graft was usually $170 \mathrm{~mm}$, and the diameter was about $5 \%$ greater than that of the aorta at stent-graft implantation. In total, $70 \mathrm{U} / \mathrm{kg}$ of heparin sodium was administered intravenously. A 22- to $24-$ French sheath was introduced transfemorally over a 0.035 -in stiff 
Inclusion criteria: acute uncomplicated TBAD without rupture, refractory pain, or rapid aortic expansion.

Exclusion criteria: younger than 18 years; aortic dissection secondary to trauma; iatrogenic injury or intramural hematoma; Marfan syndrome or Ehlers-Danlos syndrome.

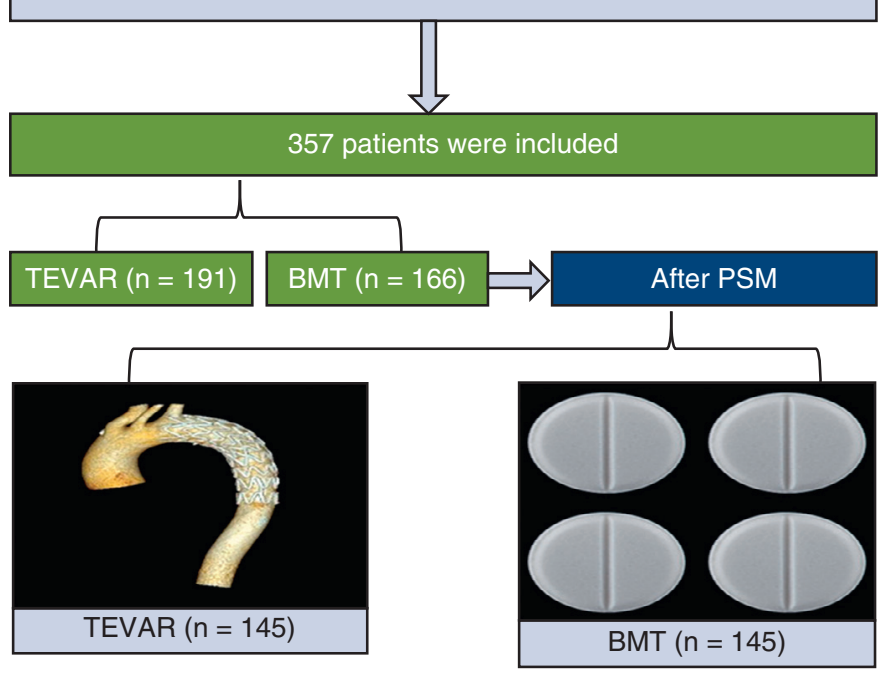

Left part
Mid-term survival: freedom from all-cause death

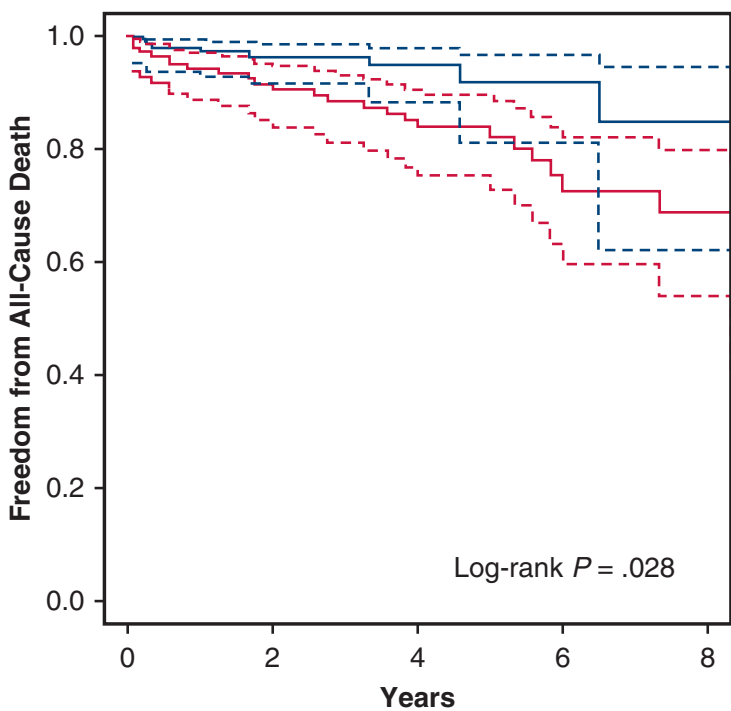

Number at risk

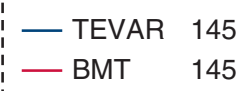

122
96

96
32

28

13

Right part

FIGURE 1. Flow chart of study population. Three hundred fifty-seven consecutive patients with acute uncomplicated TBAD were included in this retrospective study. Among them, 191 patients underwent the treatment of TEVAR, and 166 received BMT. A PSM analysis was conducted in this study to minimize selection bias and balance variables. After PSM, 145 pairs of patients were selected for analysis. We found that freedom from all-cause death in the TEVAR group was significantly greater than that of the BMT group $(P=.028)$. TBAD, Type B aortic dissection; TEVAR, thoracic endovascular aortic repair; $B M T$, best medical treatment; $P S M$, propensity score matching.

guidewire. The stent-graft was then delivered through the sheath and placed within the true lumen of the aorta. After the device was deployed, arteriography was performed to confirm the position of the device relative to the entry tear and to evaluate the size of and flow within the aortic lumens and branch vessels. Two Perclose ProGlide suture-mediated closure devices (Abbott Vascular, Inc, Santa Clara, Calif) were used to close the puncture site of the femoral artery. If the distance between the primary tear and the orifice of the LSA was less than $2 \mathrm{~cm}$, CTA or digital subtraction angiography was performed to assess the vertebrobasilar circulation to know the risk of covering the LSA. The LSA was intentionally covered without reconstruction if the occlusion of the LSA could be compensated sufficiently; otherwise, a reconstruction of the LSA was performed. An intentional coverage of the LSA is permitted, but deliberately covering the left common carotid artery (LCCA) is not permitted. A reconstruction of the LSA or LCCA was performed principally with endovascular chimney technique to secure proximal landing zone length. Adjunctive stent implantation of visceral branches or iliac arteries was performed to reduce the risk of malperfusion when it was deemed necessary based on angiographic evaluation.

\section{Definitions}

Procedure success was defined as complete coverage of the primary entry tear without a type I or III endoleak at the end of the procedure. An early adverse event was defined as any complication associated with the dissection occurring in-hospital or 30-day after confirmatory diagnosis. A late adverse event was defined as any dissection-related severe complication (including rupture, endoleak, new dissection, or retrograde type A aortic dissection $[\mathrm{A}-\mathrm{AD}]$ ) occurring more than 30 days after confirmatory diagnosis. A late intervention was defined as an endovascular repair or surgical procedure which was associated with dissection, and was performed at 1 month after the initial treatment.

\section{Statistical Analysis}

Continuous variables are expressed as mean \pm standard deviation or median with interquartile range ( 25 th- 75 th percentile), whereas categorical variables are presented as frequency and percentages. Statistical comparisons were made with the $\chi^{2}$ or Fisher exact test for categorical variables. Assumption of normality of continuous data was tested with the Shapiro-Wilk test. If assumption of normality was met, continuous variables were compared using the Student $t$ test, whereas the MannWhitney $U$ test was used for nonparametric variables.

Propensity score matching (PSM) analysis was used to minimize selection bias and balance variables. A propensity score was generated for each patient from a logistic regression model using 25 variables, which are listed in Table 1. Two pairs of matched patients (TEVAR or BMT) were obtained using a 1:1 nearest-neighbor matching algorithm with a caliper of 0.1 and without replacement. Balance of the 2 matched groups was evaluated by standardized mean differences in the matching variables. Usually a maximum standardized mean difference of 0.1 or even 0.15 is considered acceptable. $^{19}$ 
TABLE 1. Baseline covariate distribution between acute uncomplicated type B aortic dissection treated with TEVAR and BMT in the unmatched and matched population

\begin{tabular}{|c|c|c|c|c|c|c|c|c|}
\hline \multirow[b]{2}{*}{ Variable } & \multicolumn{4}{|c|}{ Unmatched population } & \multicolumn{4}{|c|}{ Matched population } \\
\hline & $\begin{array}{l}\text { TEVAR } \\
(\mathbf{n}=191)\end{array}$ & $\begin{array}{c}\text { BMT } \\
(\mathrm{n}=166)\end{array}$ & SMD & $\begin{array}{c}P \\
\text { value }\end{array}$ & $\begin{array}{c}\text { TEVAR } \\
(n=145)\end{array}$ & $\begin{array}{c}\text { BMT } \\
(n=145)\end{array}$ & SMD & $\begin{array}{c}P \\
\text { value }\end{array}$ \\
\hline Age, $y$ & $53.5 \pm 9.8$ & $55.4 \pm 11.1$ & 0.181 & .088 & $54.3 \pm 10.0$ & $54.9 \pm 10.8$ & 0.062 & .597 \\
\hline Male & $157(82.2)$ & $127(76.5)$ & 0.141 & .183 & $113(77.9)$ & $113(77.9)$ & $<0.001$ & 1.000 \\
\hline Hypertension & $124(64.9)$ & $107(64.5)$ & 0.010 & .972 & $93(64.1)$ & $92(63.4)$ & 0.014 & 1.000 \\
\hline Smoking & $91(47.6)$ & 64 (38.6) & 0.184 & .084 & $60(41.4)$ & $60(41.4)$ & $<0.001$ & 1.000 \\
\hline Drinking & $58(30.4)$ & $34(20.5)$ & 0.228 & .033 & $40(27.6)$ & $34(23.4)$ & 0.095 & .501 \\
\hline Diabetes mellitus & $6(3.1)$ & $10(6.0)$ & 0.138 & .189 & $6(4.1)$ & $8(5.5)$ & 0.064 & .784 \\
\hline COPD & $22(11.5)$ & $13(7.8)$ & 0.125 & .243 & $14(9.7)$ & $11(7.6)$ & 0.074 & .676 \\
\hline Renal insufficiency & $6(3.1)$ & $11(6.6)$ & 0.162 & .123 & $5(3.4)$ & $7(4.8)$ & 0.069 & .768 \\
\hline Coronary artery disease & $11(5.8)$ & $16(9.6)$ & 0.146 & .167 & $11(7.6)$ & $13(9.0)$ & 0.050 & .831 \\
\hline Hyperlipidemia & $8(4.2)$ & $8(4.8)$ & 0.030 & .774 & $6(4.1)$ & $8(5.5)$ & 0.064 & .784 \\
\hline History of stroke & $5(2.6)$ & $6(3.6)$ & 0.057 & .587 & $2(1.4)$ & $4(2.8)$ & 0.097 & .680 \\
\hline Atherosclerosis & $68(35.6)$ & $48(28.9)$ & 0.143 & .178 & 49 (33.8) & $45(31.0)$ & 0.059 & .707 \\
\hline Pleural effusion & 28 (14.7) & $21(12.7)$ & 0.059 & .582 & $22(15.2)$ & 17 (11.7) & 0.099 & .492 \\
\hline Dissection morphology & & & 0.169 & .112 & & & 0.087 & .555 \\
\hline Confined in thoracic aorta & $32(16.8)$ & $39(23.5)$ & & & $26(17.9)$ & $31(21.4)$ & & \\
\hline Extended to abdominal aorta & $159(83.2)$ & $127(76.5)$ & & & $119(82.1)$ & $114(78.6)$ & & \\
\hline False lumen patency & & & 0.222 & .117 & & & 0.127 & .718 \\
\hline Patent false lumen & $117(61.3)$ & 99 (59.6) & & & $91(62.8)$ & $87(60.0)$ & & \\
\hline Partial thrombosis & $74(38.7)$ & $63(38.0)$ & & & $54(37.2)$ & $57(39.3)$ & & \\
\hline Complete thrombosis & $0(0)$ & $4(2.4)$ & & & $0(0)$ & $1(0.7)$ & & \\
\hline $\begin{array}{l}\text { Maximum diameter of thoracic } \\
\text { aorta, } \mathrm{mm}\end{array}$ & $3.5(3.2-3.8)$ & $3.5(3.3-3.8)$ & 0.023 & .945 & $3.5(3.2-3.8)$ & $3.5(3.3-3.8)$ & 0.061 & .635 \\
\hline $\begin{array}{l}\text { Maximum diameter of abdominal } \\
\text { aorta, } \mathrm{mm}\end{array}$ & $2.8(2.5-3.1)$ & $2.7(2.5-3.1)$ & 0.007 & .536 & $2.8(2.5-3.1)$ & $2.7(2.5-3.1)$ & 0.041 & .941 \\
\hline Location of the primary entry tear & & & 0.213 & .047 & & & 0.074 & .636 \\
\hline$<2 \mathrm{~cm}$ from the LSA & $42(22.0)$ & $23(13.9)$ & & & $26(17.9)$ & $22(15.2)$ & & \\
\hline$>2 \mathrm{~cm}$ from the LSA & $149(78.0)$ & $143(86.1)$ & & & $119(82.1)$ & $123(84.8)$ & & \\
\hline $\mathrm{SBP}$ on admission, $\mathrm{mm} \mathrm{Hg}$ & $140(128-154)$ & $140(124-153)$ & 0.117 & .363 & $140(125-152)$ & $140(125-154)$ & 0.008 & .974 \\
\hline DBP on admission, $\mathrm{mm} \mathrm{Hg}$ & $80(72-94)$ & $83(70-92)$ & 0.057 & .636 & $80(71-92)$ & $83(70-90)$ & 0.050 & .656 \\
\hline LVEF, \% & $64(61-66)$ & $64(60-66)$ & 0.099 & .611 & $65(62-66)$ & $64(60-66)$ & 0.078 & .636 \\
\hline Creatinine, $\mu \mathrm{mol} / \mathrm{L}$ & $74.2(62.6-88.6)$ & $77.9(65.2-94.2)$ & 0.204 & .124 & $72.9(62.6-88.6)$ & $74.7(65.1-92.6)$ & 0.082 & .267 \\
\hline ALT, U/L & $24.0(16.0-47.0)$ & $23.0(16.0-38.0)$ & 0.072 & .223 & $24.0(16.0-48.0)$ & $22.0(16.0-37.0)$ & 0.027 & .133 \\
\hline AST, U/L & $22.0(16.0-31.0)$ & $21.0(15.8-34.0)$ & 0.141 & .812 & $22.0(16.0-31.0)$ & $20.0(16.0-29.0)$ & 0.039 & .384 \\
\hline Symptoms at presentation & & & 0.114 & .562 & & & 0.094 & .729 \\
\hline Chest and back pain & $163(85.3)$ & $142(85.5)$ & & & $124(85.5)$ & $125(86.2)$ & & \\
\hline Abdominal pain & $17(8.9)$ & $11(6.6)$ & & & $12(8.3)$ & $9(6.2)$ & & \\
\hline Other symptoms & $11(5.8)$ & $13(7.8)$ & & & $9(6.2)$ & $11(7.6)$ & & \\
\hline
\end{tabular}

Categorical variables are reported as frequency and percentage; continuous variables are reported as mean \pm standard deviation or median (25th-75th percentile). TEVAR, Thoracic endovascular aortic repair; $B M T$, best medical treatment; $S M D$, standardized mean difference; $C O P D$, chronic obstructive pulmonary disease; $L S A$, left subclavian artery; $S B P$, systolic blood pressure; $D B P$, diastolic blood pressure; $L V E F$, left ventricle ejection fraction; $A L T$, alanine aminotransferase; $A S T$, aspartate aminotransferase.

For the time-to-event analysis, the primary outcome of interest was mortality, and freedom from mortality was estimated using the KaplanMeier survival method and differences in survival curves were analyzed with the log-rank test. Secondary outcomes of interest were aorta-related adverse event: rupture, retrograde type A-AD, new dissection, type I endoleak, and late intervention. The Cox proportional hazards model on the matched pairs was used to identify predominant risk factors for all-cause mortality. $P<.1$ in the univariate analysis was defined for selecting 
TABLE 2. Early outcomes in the unmatched and matched population

\begin{tabular}{|c|c|c|c|c|c|c|}
\hline \multirow[b]{2}{*}{ Variable } & \multicolumn{3}{|c|}{$\begin{array}{r}\text { Unmatched population } \\
\end{array}$} & \multicolumn{3}{|c|}{$\begin{array}{r}\text { Matched population } \\
\end{array}$} \\
\hline & TEVAR $(n=191)$ & BMT $(n=166)$ & $P$ value & $\overline{\text { TEVAR }(n=145)}$ & BMT $(n=145)$ & $P$ value \\
\hline Hospital stay, d & $10.8 \pm 2.7$ & $11.2 \pm 8.6$ & .324 & $10.9 \pm 2.8$ & $11.2 \pm 8.0$ & .612 \\
\hline 30-d mortality & $1(0.5)$ & $4(2.4)$ & .188 & $1(0.7)$ & $3(2.1)$ & .622 \\
\hline Early events & $23(12.0)$ & $5(3.0)$ & .001 & 17 (11.7) & $4(2.8)$ & .003 \\
\hline Acute renal failure & $1(0.5)$ & $0(0)$ & & $1(0.7)$ & $0(0)$ & \\
\hline Type I endoleak & $16(8.4)$ & NA & & $12(8.3)$ & NA & \\
\hline Stroke & $2(1.0)$ & $0(0)$ & & $1(0.7)$ & $0(0)$ & \\
\hline Rupture & $0(0)$ & $4(2.4)$ & & $0(0)$ & $3(2.1)$ & \\
\hline Retrograde type A-AD & $3(1.6)$ & $0(0)$ & & $2(1.4)$ & $0(0)$ & \\
\hline Organ failure & $1(0.5)$ & $1(0.6)$ & & $1(0.7)$ & $1(0.7)$ & \\
\hline
\end{tabular}

Values are mean \pm standard deviation or $\mathrm{n}(\%)$. TEVAR, Thoracic endovascular aortic repair; $B M T$, best medical treatment; $N A$, not available; $A-A D$, type A aortic dissection.

variables for entry into the multivariable regression analysis. Late intervention and aorta-related events were evaluated with a competing risk analysis with all-cause death as a competing risk. Between-group differences were assessed using the Gray test for cumulative incidence estimates.

All of these statistical tests were 2-sided, and the significance level was $<.05$. Statistical analyses were performed using SPSS, version 25.0 (SPSS, Chicago, Ill) and R 3.6.1 (R Development Core Team, Vienna, Austria).

\section{RESULTS}

\section{Baseline Characteristics}

After PSM, 2 groups of 145 subjects were obtained. The baseline characteristics before and after matching ae listed in Table 1. Before matching, the TEVAR group had more drinkers and had a larger percentage of the distance $<2.0 \mathrm{~cm}$ between the primary entry tear and the LSA. After matching, no statistically significant differences were observed between the 2 groups in all baseline variables.

\section{TEVAR Procedure}

The median time interval between symptom onset and TEVAR in our study was 7 days (interquartile range, 411 days) in the unmatched and matched population. In the matched population, the technical success (coverage of the primary tear) was achieved in $143(98.6 \%)$ patients in the TEVAR group: 2 type I endoleaks were confirmed by angiography after TEVAR. A total of 192 stent-grafts were implanted in 145 patients, including 168 stent-grafts implanted in descending thoracic aorta and 24 adjunctive stent-grafts. Among the 168 stent-grafts that were implanted in the descending thoracic aorta, $125(86.2 \%)$ patients received 1 stent-graft each, $17(11.7 \%)$ patients received 2 stent-grafts each, and $3(2.1 \%)$ patients received 3 stent-grafts each. Five different types of stent-grafts were used in the procedure of TEVAR: Talent (Medtronic, Inc, Minneapolis, Minn) was used in 93 patients, E-vita (JOTEC $\mathrm{GmbH}$, Hechingen, Germany) in 27 patients, Zenith (Cook, Bloomington, Ind) in 7 patients, Aegis (Microport, Shanghai, China) in 20 patients, and Ankura (Lifetech
Scientific, Shenzhen, China) in 21 patients. Among the 24 adjunctive stent-grafts, $4(2.8 \%)$ chimney stent-grafts were implanted in the LSA, $4(2.8 \%)$ chimney stentgrafts were implanted in the LCCA, $12(8.3 \%)$ stentgrafts were implanted in the abdominal aorta, $1(0.7 \%)$ stent-graft was implanted in the renal artery, and $3(2.1 \%)$ stent-grafts were implanted in the iliac artery. The LSA was completely covered in $9(6.2 \%)$ patients and partially in $35(24.1 \%)$ patients.

\section{Medical Management}

Among the 290 matched patients, 185 (63.8\%) patients (BMT group, $\mathrm{n}=92$; TEVAR group, $\mathrm{n}=93$ ) had elevated SBP, which dropped to below $120 \mathrm{~mm} \mathrm{Hg}$ with antihypertensive treatment during hospitalization. In addition, an aortic CTA scan was used for monitoring the changes of the aortic characteristics during the hospitalization in the medical management group. After discharge, all the patients continued to receive antihypertensive therapy, which helped to regulate blood pressure to below 140/90 $\mathrm{mm} \mathrm{Hg}$ during the mid- and long-term follow-up.

\section{Early Outcomes}

Although there was no statistically significant difference in the 30-day mortality between the TEVAR and BMT groups, the early adverse event rates in the TEVAR group were significantly greater than that of the BMT group $(11.7 \%$ vs $2.8 \% ; P=.003)$. Details of the early outcomes are listed in Table 2.

The 30-day mortality rate in the TEVAR group was $0.7 \%$. One patient was admitted to the hospital with a sudden stroke 22 days after the TEVAR procedure. The choice of a conservative treatment did not work, and the patient died 1 day after the commencement of the treatment. In addition, 2 mild retrograde type A aortic dissections were treated conservatively and followed up closely. One patient experienced organ failure, but completely recovered after 
TABLE 3. Late outcomes in the matched population

\begin{tabular}{|c|c|c|c|}
\hline Variable & $\begin{array}{c}\text { TEVAR } \\
(\mathrm{n}=145)\end{array}$ & $\begin{array}{c}\text { BMT } \\
(n=145)\end{array}$ & $\begin{array}{c}P \\
\text { value }\end{array}$ \\
\hline $\begin{array}{l}\text { Freedom from all- } \\
\text { cause death, \% }\end{array}$ & & & .028 \\
\hline $1 \mathrm{y}$ & $97.2 \%(92.7-98.9)$ & $94.2 \%(88.8-97.1)$ & \\
\hline $3 \mathrm{y}$ & $96.4 \%$ (91.6-98.5) & $88.5 \%(81.1-93.1)$ & \\
\hline $5 \mathrm{y}$ & $91.9 \%(81.1-96.7)$ & $82.2 \%(72.9-88.5)$ & \\
\hline $\begin{array}{l}\text { Freedom from aortic- } \\
\text { related death, } \%\end{array}$ & & & .044 \\
\hline $1 \mathrm{y}$ & $97.8 \%(93.6-99.3)$ & $94.2 \%(88.8-97.1)$ & \\
\hline $3 y$ & $97.2 \%(92.6-98.9)$ & $90.2 \%(83.3-94.4)$ & \\
\hline $5 \mathrm{y}$ & $94.1 \%(82.9-98.1)$ & $86.1 \%(77.5-91.7)$ & \\
\hline $\begin{array}{c}\text { Cumulative incidence } \\
\text { of rupture, } \%\end{array}$ & & & .024 \\
\hline $1 \mathrm{y}$ & $2.1 \%(0.6-5.6)$ & $5.7 \%(2.7-10.5)$ & \\
\hline $3 y$ & $2.1 \%(0.6-5.6)$ & $9.7 \%(5.2-15.9)$ & \\
\hline $5 \mathrm{y}$ & $5.1 \%(1.1-14.1)$ & $13.7 \%(7.8-21.3)$ & \\
\hline $\begin{array}{l}\text { Cumulative incidence } \\
\text { of retrograde type } \\
\text { A-AD, \% }\end{array}$ & & & .610 \\
\hline $1 \mathrm{y}$ & $2.8 \%(0.9-6.5)$ & $0.7 \%(0.1-3.7)$ & \\
\hline $3 y$ & $3.7 \%(1.4-8.0)$ & $1.7 \%(0.3-5.5)$ & \\
\hline $5 y$ & $3.7 \%(1.4-8.0)$ & $2.9 \%(0.7-7.7)$ & \\
\hline $\begin{array}{l}\text { Cumulative incidence } \\
\text { of new dissection, } \\
\%\end{array}$ & & & .529 \\
\hline $1 \mathrm{y}$ & $2.1 \%(0.6-5.6)$ & $2.9 \%(1.0-6.8)$ & \\
\hline $3 y$ & $3.6 \%(1.3-7.7)$ & $3.9 \%(1.4-8.3)$ & \\
\hline $5 \mathrm{y}$ & $3.6 \%(1.3-7.7)$ & $5.0 \%(2.0-10.2)$ & \\
\hline $\begin{array}{l}\text { Cumulative incidence } \\
\text { of type I } \\
\text { endoleak, \% }\end{array}$ & & & NA \\
\hline $1 \mathrm{y}$ & $4.9 \%(2.2-9.3)$ & NA & \\
\hline $3 y$ & $6.1 \%(2.8-11.4)$ & NA & \\
\hline $5 y$ & $13.2 \%(4.9-25.8)$ & NA & \\
\hline $\begin{array}{l}\text { Cumulative incidence } \\
\text { of late } \\
\text { intervention, } \%\end{array}$ & & & .214 \\
\hline $1 \mathrm{y}$ & $2.1 \%(0.6-5.5)$ & $6.6 \%(3.2-11.6)$ & \\
\hline $3 y$ & $3.6 \%(1.3-7.6)$ & $6.6 \%(3.2-11.6)$ & \\
\hline $5 \mathrm{y}$ & $6.0 \%(1.9-13.3)$ & $9.0 \%(4.6-15.1)$ & \\
\hline
\end{tabular}

Kaplan-Meier estimates for all-cause mortality and aortic-related mortality. Cumulative incidence estimates for rupture, retrograde type $\mathrm{A}-\mathrm{AD}$, new dissection, type I endoleak, and late intervention with death as a competing risk. Parentheses indicate $95 \%$ confidence intervals. TEVAR, Thoracic endovascular aortic repair; $B M T$, best medical treatment; $N A$, not available; $A-A D$, type A aortic dissection.

10 days of treatment at the intensive care unit. A total of 12 type I endoleaks were observed in the 30-day follow up period. These patients were left untreated but followed up closely. One patient experienced acute renal failure after the TEVAR procedure but completely recovered after active therapy. No paraplegia or paraparesis was found in these patients.
In the BMT group, the 30-day mortality was $2.1 \%$. Three patients all died of sudden aortic rupture during hospitalization or at home after discharge. One patient experienced organ failure, but he improved before discharge.

\section{Late Outcomes}

The late outcomes in the matched population are reported in Table 3. Table 3 reports the freedom from death and the cumulative incidence rates for the aortic-related adverse events at 1,3 , and 5 years. A total of 30 late deaths were reported, including 20 aortic-related late deaths, 19 resulting from aortic rupture and 1 from retrograde type A aortic dissection. A total of 8 deaths were categorized as aorticunrelated late deaths (cardiac-related deaths, $\mathrm{n}=2$; cancer-related deaths, $\mathrm{n}=3$; deaths caused by multiorgan failures, $\mathrm{n}=2$; death caused by severe injury, $\mathrm{n}=1$ ). The reasons for the other 2 deaths were unknown.

The freedom from all-cause death in the TEVAR group at 1,3 , and 5 years was $97.2 \%, 96.4 \%$, and $91.9 \%$, respectively, and in the BMT group was $94.2 \%, 88.5 \%$, and $82.2 \%$, respectively. Freedom from all-cause mortality in the TEVAR group was significantly greater than that of the BMT group $(P=.028)$ (Figure 2, A). Furthermore, freedom from aortic-related death in the TEVAR group at 1,3 , and 5 years was $97.8 \%, 97.2 \%$, and $94.1 \%$, respectively, and in the BMT group was $94.2 \%, 90.2 \%$, and $86.1 \%$, respectively. Freedom from aortic-related mortality in the TEVAR group was significantly greater than that of the BMT group $(P=.044)$ (Figure $2, B)$.

Univariate and multivariable analysis of all-cause death in the matched population are reported in Table 4. Univariate Cox-hazard regression analysis revealed that BMT, older age, complete thrombosis, the distance between the primary entry tear and the LSA $<2.0 \mathrm{~cm}$, and greater aspartate aminotransferase and alanine aminotransferase were the significant risk factors for all-cause death. Multivariable Cox-hazard regression analysis demonstrated that the older age (hazard ratio [HR], 1.04; 95\% confidence interval [CI], 1.01-1.08, $P=.013$ ), BMT (HR, 2.33; 95\% CI, 1.08-5.05, $P=.032$ ), and the distance between the primary entry tear and the LSA $<2.0 \mathrm{~cm}$ (HR, 2.30; 95\% CI, 1.06-4.99, $P=.035)$ were significant risk factors for all-cause death. In contrast, TEVAR was found to be a significant positive prognostic factor of all-cause death. The cumulative incidence of rupture at 5 years was $5.1 \%$ in the TEVAR group and $13.7 \%$ in the BMT group, The Gray test revealed that the difference in the cumulative incidence of rupture between the 2 groups was statistically significant $(P=.024)$ (Figure 3). Meanwhile, there were no statistically significant differences in the cumulative incidence of retrograde type $\mathrm{A}-\mathrm{AD}$ and new dissection between the 2 groups $(P=.610 ; P=.529$, respectively). The cumulative incidence of type I endoleak at 1, 3, 5 years in the TEVAR group was $4.9 \%, 6.1 \%, 13.2 \%$, respectively. 


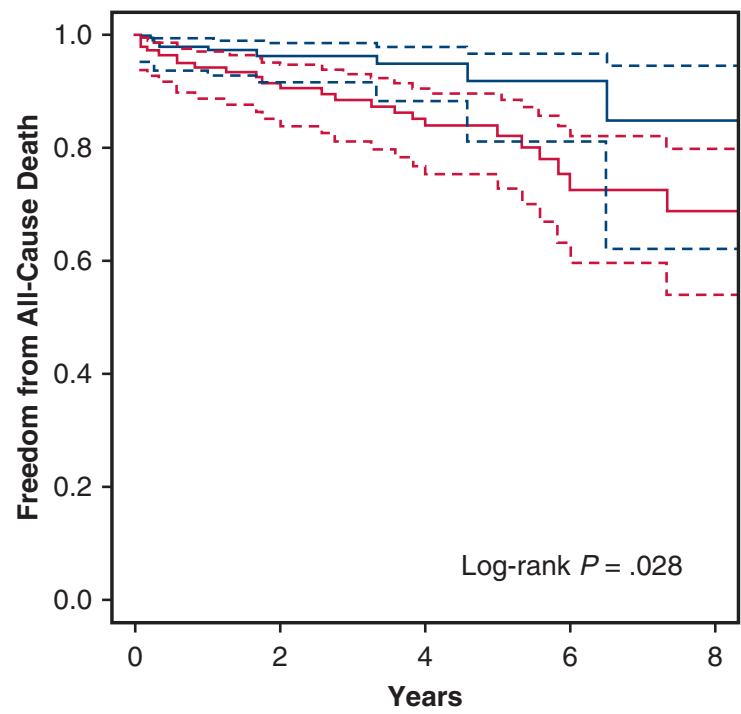

Number at risk

- TEVAR 145

BMT 145

A

FIGURE 2. Kaplan-Meier survival analysis in the matched patients who were treated with TEVAR or BMT. The differences between the 2 groups were assessed with log-rank test. A, Freedom from all-cause death between the 2 groups. Freedom from all-cause death in the TEVAR group was significantly greater than that of the BMT group $(P=.028)$. B, Freedom from aortic-related death between the 2 groups. Freedom from aortic-related death in the TEVAR group was significantly greater than that of the BMT group $(P=.044)$. TEVAR, Thoracic endovascular aortic repair; BMT, best medical treatment.

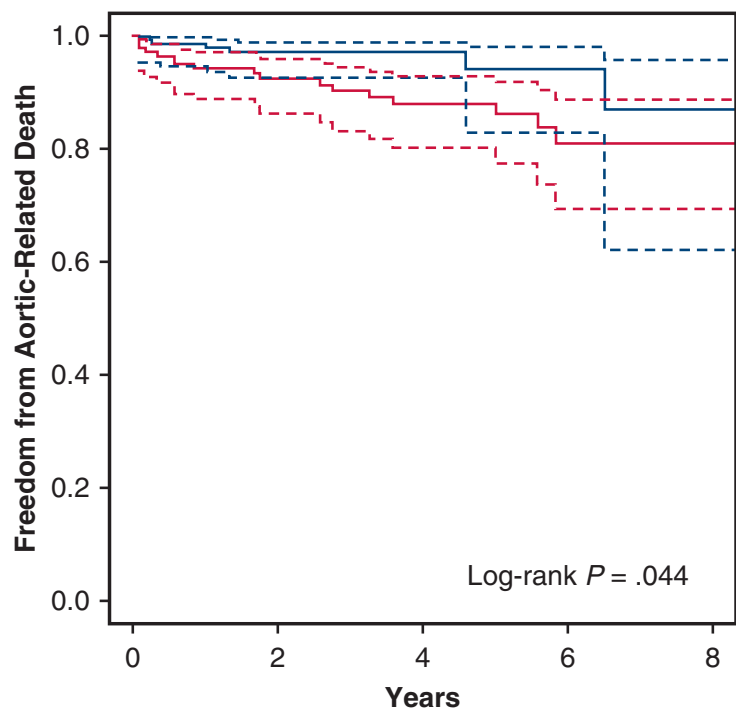

\begin{tabular}{cccccc}
\multicolumn{2}{c}{ Number at risk } & & & \\
TEVAR & 145 & 131 & 131 & 32 & 13 \\
\hline BMT & 145 & 100 & 77 & 30 & 30
\end{tabular}

B
30
In the TEVAR group, $6(4.1 \%)$ patients needed reintervention for type I endoleak ( 2 of 6 ), abdominal aortic aneurysm expansion ( 1 of 6 ), dissection extension ( 1 of 6 ), and retrograde type $\mathrm{A}-\mathrm{AD}$ (2 of 6 ). In the $\mathrm{BMT}$ group, 12 $(8.3 \%)$ patients needed operation with TEVAR or open surgery, and the reasons were false lumen dilation (9 of 12) and dissection extension ( 3 of 12). Although there was no statistically significant difference in the cumulative incidence of late intervention between the 2 groups $(P=.214)$ (Figure 4), 4 patients in the BMT group were died even after operation, whereas there were no deaths in the TEVAR group.

In subgroup analysis, no statistically significant postoperative differences were observed among patients that required a chimney technique compared with the groups in whom the LSA was covered (Table E1). Meanwhile, no statistically significant postoperative differences were observed among patients of whether to accept adjunctive stent implantation of visceral branches in the TEVAR group (Table E2).

\section{DISCUSSION}

A long-standing consensus is that patients with acute uncomplicated TBAD should be treated medically. However, the long-term outcome of acute uncomplicated TBAD 
TABLE 4. Univariate and multivariable analysis of all-cause death in the matched population (Cox hazard analysis)

\begin{tabular}{|c|c|c|c|c|}
\hline \multirow[b]{2}{*}{ Variable } & \multicolumn{2}{|c|}{ Univariate analysis } & \multicolumn{2}{|c|}{ Multivariate analysis } \\
\hline & HR $(95 \%$ CI) & $P$ value & HR $(95 \%$ CI) & $P$ value \\
\hline BMT & $2.31(1.07-5.00)$ & .033 & $2.33(1.08-5.05)$ & .032 \\
\hline Age, $y$ & $1.05(1.01-1.08)$ & .011 & $1.04(1.01-1.08)$ & .013 \\
\hline Male & $1.04(0.45-2.38)$ & .932 & & \\
\hline Hypertension & $1.33(0.67-2.64)$ & .408 & & \\
\hline Smoking & $1.15(0.58-2.27)$ & .686 & & \\
\hline Drinking & $0.56(0.23-1.36)$ & .199 & & \\
\hline Diabetes mellitus & $1.20(0.29-5.03)$ & .799 & & \\
\hline COPD & $1.35(0.52-3.49)$ & .538 & & \\
\hline Renal insufficiency & $0.55(0.75-4.02)$ & .554 & & \\
\hline Coronary artery disease & $0.68(0.16-2.85)$ & .597 & & \\
\hline Hyperlipidemia & $0.04(0.00-6.62)$ & .214 & & \\
\hline History of stroke & $1.64(0.39-6.89)$ & .499 & & \\
\hline Atherosclerosis & $1.15(0.57-2.33)$ & .694 & & \\
\hline Pleural effusion & $0.45(0.14-1.48)$ & .187 & & \\
\hline Dissection morphology & $1.35(0.63-2.89)$ & .447 & & \\
\hline \multicolumn{5}{|l|}{ False lumen patency } \\
\hline Patent false lumen & Ref & Ref & Ref & Ref \\
\hline Partial thrombosis & $1.64(0.81-3.31)$ & .169 & $1.68(0.83-3.42)$ & .151 \\
\hline Complete thrombosis & $5.61(0.74-42.72)$ & .096 & $2.28(0.29-17.91)$ & .435 \\
\hline Maximum diameter of thoracic aorta, $\mathrm{mm}$ & $1.49(0.80-2.77)$ & .205 & & \\
\hline Maximum diameter of abdominal aorta, $\mathrm{mm}$ & $1.20(0.61-2.34)$ & .595 & & \\
\hline Location of the primary entry tear & $2.20(1.01-4.77)$ & .046 & $2.30(1.06-4.99)$ & .035 \\
\hline SBP on admission, $\mathrm{mm} \mathrm{Hg}$ & $0.99(0.98-1.01)$ & .394 & & \\
\hline DBP on admission, $\mathrm{mm} \mathrm{Hg}$ & $1.00(0.99-1.03)$ & .372 & & \\
\hline LVEF, \% & $1.00(0.94-1.06)$ & .999 & & \\
\hline Creatinine, $\mu \mathrm{mol} / \mathrm{L}$ & $1.00(0.99-1.01)$ & .804 & & \\
\hline ALT, U/L & $0.97(0.94-1.00)$ & .019 & $0.97(0.94-1.01)$ & .096 \\
\hline AST, U/L & $0.97(0.95-1.00)$ & .079 & $1.00(0.97-1.02)$ & .778 \\
\hline \multicolumn{5}{|l|}{ Symptoms at presentation } \\
\hline Chest and back pain & $0.81(0.24-2.67)$ & .724 & & \\
\hline Abdominal pain & $2.11(0.46-9.63)$ & .335 & & \\
\hline Other symptoms & Ref & Ref & & \\
\hline
\end{tabular}

$H R$, Hazard ratio; $C I$, confidence interval; $B M T$, best medical treatment; $C O P D$, chronic obstructive pulmonary disease; $S B P$, systolic blood pressure; $D B P$, diastolic blood pressure; $L V E F$, left ventricle ejection fraction; $A L T$, alanine aminotransferase; $A S T$, aspartate aminotransferase.

randomized trial on acute dissection, compared BMT with the combination treatment of thoracic stent grafting with BMT for patients with acute uncomplicated TBAD, and it reported that there were no deaths in either the TEVAR or BMT group during the first 30 days. These studies with low mortality had common patient inclusion criteria that was patients with uncomplicated TBAD.
In this study, the early adverse event rates were $11.7 \%$ in the TEVAR group and $2.8 \%$ in the BMT group. The early adverse event rates in the BMT group were consistent with findings from previous studies. ${ }^{24,25}$ Previous studies reported that the early adverse event rates of TEVAR for complicated TBAD were $2.4 \% \sim 33.3 \%,{ }^{26-28}$ whereas there were relatively few reports about the early adverse 


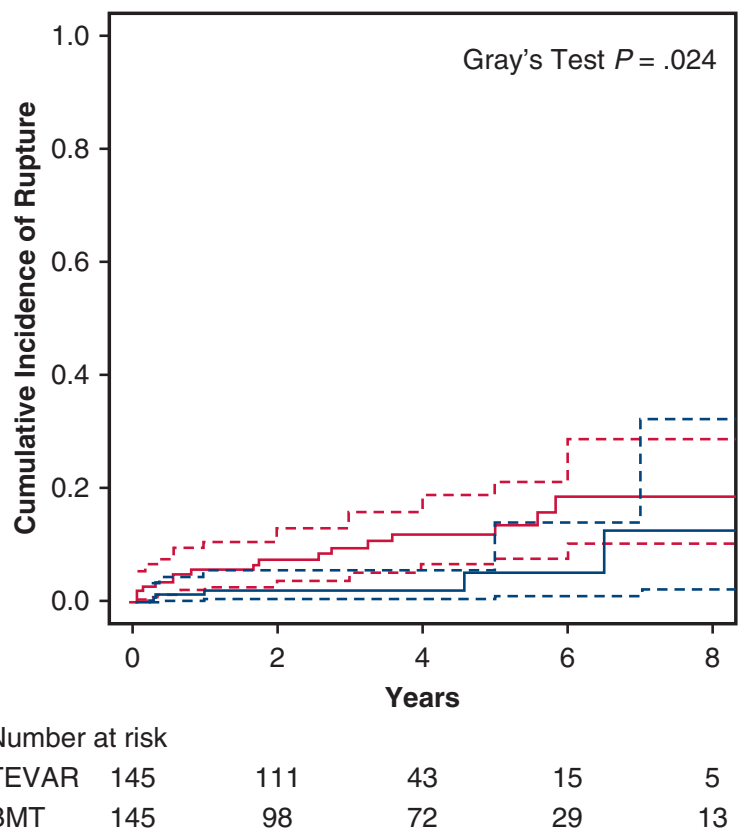

FIGURE 3. The cumulative incidence of the aortic-related events with allcause death as a competing risk in the matched patients who were treated with TEVAR or BMT. The differences were assessed with the Gray test. The cumulative incidence of rupture in the BMT group was significantly greater than that of the TEVAR group $(P=.024)$. TEVAR, Thoracic endovascular aortic repair; $B M T$, best medical treatment.

event rates of TEVAR for uncomplicated TBAD. Recently, a multicenter retrospective study reported that the early adverse event rates of TEVAR and BMT in the treatment of acute uncomplicated TBAD were $10.5 \%$ and $4.5 \%$, respectively. ${ }^{12}$ This result was close to our finding, but the early adverse event rates in the TEVAR group in our study were significantly greater than that of in the BMT group. The most common complications during and after TEVAR included endoleak, retrograde type A dissection, cerebral ischemia, and paraplegia. ${ }^{29-31}$ Type-I endoleak is a matter of concern in all studies on thoracic endografting and is reported quite frequently. In our study, 12 cases $(8.3 \%)$ with type-I endoleak were observed in the early stage. Interestingly, we found that $8(66.7 \%)$ of these cases were used the same brand of the stent, that was the E-vita stentgrafts. Zipfel and colleagues ${ }^{32}$ also reported previously that the use of E-vita stent-grafts resulted in a greater incidence of $18 \%$ early proximal endoleaks, compared with the authors' Talent experience with an incidence of $10 \%$ persistent endoleaks. Despite the high rate of early adverse events after TEVAR, most of them appeared to be mild or transient. No significant expansion of early endoleak was reported at 1 -year follow-up, and only 1 of the patients experiencing late death had an early endoleak.

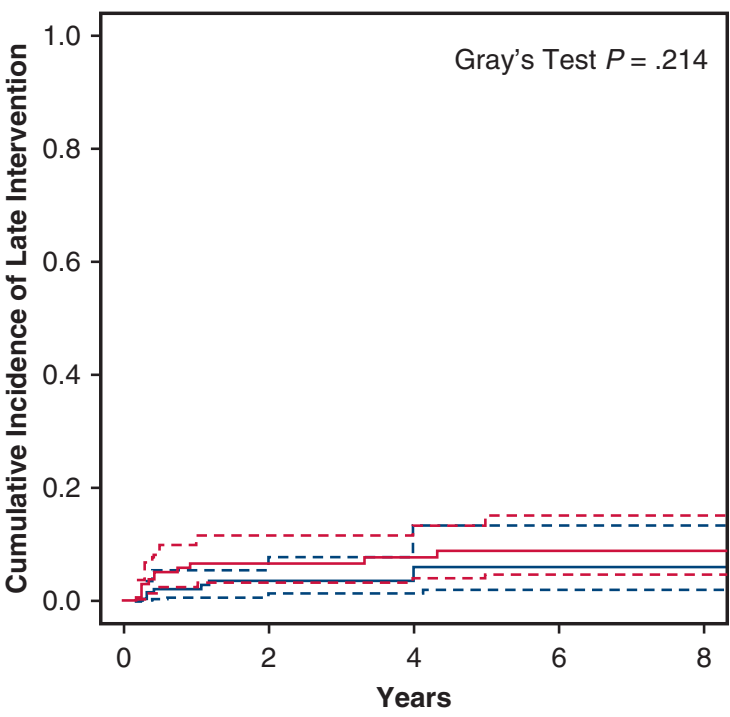

Number at risk

- TEVAR 145

- BMT 145

101

37

13

4

FIGURE 4. The cumulative incidence of the late intervention with allcause death as a competing risk in the matched patients who were treated with TEVAR or BMT. The difference was assessed with the Gray test. The difference in the late intervention between the two groups was not statistically significant. TEVAR, Thoracic endovascular aortic repair; BMT, best medical treatment.

Survival rates in patients with TBAD after TEVAR have been reported to range from $81.5 \%$ to $91.9 \%$ at 1 year and from $76 \%$ to $89.2 \%$ at 5 years. ${ }^{9}, 12,33,34$ In medically treated patients, survival rates ranged from $84 \%$ to $90.2 \%$ at 1 year

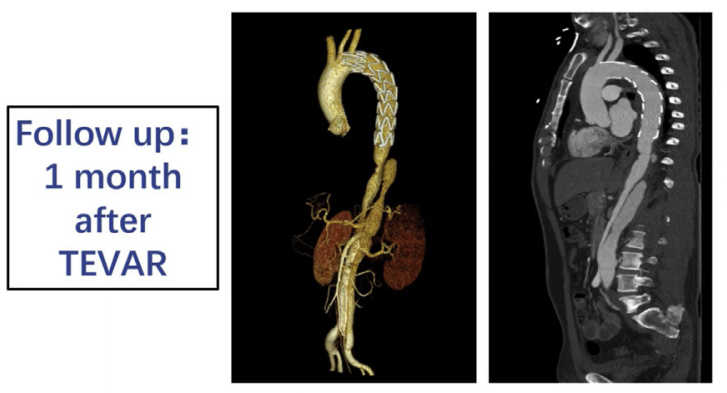

VIDEO 1. The process of admission diagnosis in a patient with acute uncomplicated TBAD, the treatment for this patient with TEVAR procedure, and the patient's follow-up. TBAD, Type B aortic dissection; TEVAR, thoracic endovascular aortic repair. Video available at: https://www.jtcvs. org/article/S0022-5223(19)40469-8/fulltext. 
and from $60 \%$ to $86.8 \%$ at 5 -year. ${ }^{9,12,34}$ Although the ADSORB trial is the first randomized trial on acute dissection, it was underpowered for survival and had a cut-off at 1-year follow-up. The INSTEAD-XL (Investigation of Stent Grafts in Aortic Dissection with Extended Follow-Up) trial is the only prospective randomized trial to investigate the long-term outcomes of TEVAR for uncomplicated aortic dissections. ${ }^{35}$ It showed that TEVAR improved the 5-year overall and aortaspecific survival for patients with uncomplicated aortic dissections: the overall survival $(88.9 \%$ vs $80.7 \%)$ and aorta-specific survival $(93.1 \%$ vs $80.7 \%)$ at 5 -year were significantly greater with TEVAR than with optimal medical treatment alone. In the present study, the cumulative 5-year survival and aorta-related survival for TEVAR were $91.9 \%$ and $94.1 \%$, respectively, and for BMT were $82.2 \%$ and $86.1 \%$, respectively. These results in our study were close to the results of INSTEAD study. Therefore, the results of our study confirmed the results of INSTEAD study that the treatment of TEVAR improved the survival for patients with uncomplicated aortic dissections compared with BMT alone.

As for late adverse events in our study, although the difference in the number of complications between the 2 groups was not statistically significant, the BMT group appeared to have more fatal complications. Type I endoleak $(6.9 \%)$ was the most common complication in the TEVAR group. However, type I endoleak was not a permanent complication of TEVAR, and 4 type I endoleaks disappeared in the follow-up CTA imaging. In the BMT group, the most common complication was aortic rupture $(9.7 \%)$. The cumulative incidence of this complication in the BMT group was significantly greater than that of the TEVAR group. In addition, although there was no statistically significant difference in the cumulative incidence of late intervention between the 2 groups, 4 patients in the BMT group died even after operation, whereas there were no deaths in the TEVAR group after reoperation. It indicated that the prognosis of patients after reintervention in the TEVAR group may be better than that of in the BMT group.

\section{Study Limitations}

Our study has several limitations. First, our study was retrospective, and potential selection bias in our population could not be completely avoided even after PSM analysis. Second, although the sample size was large enough, and the follow-up period was comparatively long, the relatively large proportion of patients in recent years may be linked partially to good results. Lastly, various types and constructions of stent grafts and both improved technical expertise and stent-graft design may impact our findings.

\section{CONCLUSIONS}

Although there were many cases of early adverse events after TEVAR in our investigation, most of them were mild and transient. In a long-run perspective, TEVAR for acute uncomplicated TBAD patients showed an improved midterm survival and fewer late aortic ruptures compared with BMT alone. Therefore, TEVAR may be considered as the first option to improve the late outcomes in patients with acute uncomplicated TBAD (Video 1).

\section{Conflict of Interest Statement}

Authors have nothing to disclose with regard to commercial support.

\section{References}

1. Tsai TT, Evangelista A, Nienaber CA, Myrmel T, Meinhardt G, Cooper JV, et al Partial thrombosis of the false lumen in patients with acute type B aortic dissection. N Engl J Med. 2007;357:349-59.

2. Durham CA, Aranson NJ, Ergul EA, Wang LJ, Patel VI, Cambria RP, et al. Aneurysmal degeneration of the thoracoabdominal aorta after medical management of type B aortic dissections. J Vasc Surg. 2015;62:900-6.

3. Luebke T, Brunkwall J. Outcome of patients with open and endovascular repair in acute complicated type B aortic dissection: a systematic review and metaanalysis of case series and comparative studies. J Cardiovasc Surg. 2010;51: 613-32.

4. Erbel R, Aboyans V, Boileau C, Bossone E, Di Bartolomeo R, Eggebrecht H, et al. 2014 ESC Guidelines on the diagnosis and treatment of aortic diseases. Eur Heart J. 2014;35:2873-93.

5. Estrera AL, Miller CC, Goodrick J, Porat EE, Achouh PE, Dhareshwar J, et al. Update on outcomes of acute type B aortic dissection. Ann Thorac Surg. 2007; 83:S842-5.

6. Akin I, Kische S, Ince H, Nienaber CA. Indication, timing and results of endovascular treatment of type B dissection. Eur J Vasc Endovasc. 2009;37:289-96.

7. Tsai TT, Trimarchi S, Nienaber CA. Acute aortic dissection: perspectives from the International Registry of Acute Aortic Dissection (IRAD). Eur J Vasc Endovasc. 2009;37:149-59.

8. Trimarchi S, Tolenaar JL, Tsai TT, Froehlich J, Pegorer M, Upchurch GR, et al. Influence of clinical presentation on the outcome of acute B aortic dissection: evidences from IRAD. J Cardiovasc Surg. 2012;53:161-8.

9. Fattori R, Montgomery D, Lovato L, Kische S, Di Eusanio M, Ince H, et al. Survival after endovascular therapy in patients with type $\mathrm{b}$ aortic dissection: a report from the International Registry of Acute Aortic Dissection (IRAD). JACC Cardiovasc Interv. 2013;6:876-82.

10. Nienaber CA, Rousseau H, Eggebrecht H, Kische S, Fattori R, Rehders TC, et al Randomized Comparison of Strategies for Type B Aortic Dissection The INvestigation of STEnt Grafts in Aortic Dissection (INSTEAD) Trial. Circulation. 2009; 120:2519-28.

11. Qin YL, Deng G, Li TX, Wang WP, Teng GJ. Treatment of acute type-B aortic dissection thoracic endovascular aortic repair or medical management alone? JACC Cardiovasc Interv. 2013;6:185-91.

12. Qin YL, Wang F, Li TX, Ding W, Deng G, Xie B, et al. Endovascular repai compared with medical management of patients with uncomplicated type B acute aortic dissection. J Am Coll Cardiol. 2016;67:2835-42.

13. Shah TR, Rockman CB, Adelman MA, Maldonado TS, Veith FJ, Mussa FF Nationwide comparative impact of thoracic endovascular aortic repair of acute uncomplicated type B aortic dissections. Vasc Endovasc Surg. 2014;48:230-3.

14. Garbade J, Jenniches M, Borger MA, Barten MJ, Scheinert D, Gutberlet M, et al Outcome of patients suffering from acute type B aortic dissection: a retrospective single-centre analysis of 135 consecutive patients. Eur J Cardiothorac Surg. 2010;38:285-92.

15. Nienaber CA, Kische S, Akin I, Rousseau H, Eggebrecht H, Fattori R, et al Strategies for subacute/chronic type B aortic dissection: the Investigation Of Stent Grafts in Patients with type B Aortic Dissection (INSTEAD) trial 1 year outcome. J Thorac Cardiovasc Surg. 2010;140:S101-8; discussion S142-6. 
16. Brunkwall J, Lammer J, Verhoeven E, Taylor R. ADSORB: A Study on the Efficacy of Endovascular Grafting in Uncomplicated Acute Dissection of the Descending Aorta. Eur J Vasc Endovasc. 2012;44:31-6.

17. Brunkwall J, Kasprzak P, Verhoeven E, Heijmen R, Taylor P, Alric P, et al. Endovascular repair of acute uncomplicated aortic type b dissection promotes aortic remodelling: 1 year results of the ADSORB trial. Eur J Vasc Endovasc. 2014; 48:285-91.

18. Trimarchi S, Eagle KA, Nienaber CA, Pyeritz RE, Jonker FHW, Suzuki T, et al. Importance of refractory pain and hypertension in acute Type B aortic dissection: insights from the International registry of acute aortic dissection (IRAD). Circulation. 2010;122:1283-9.

19. Rufa MI, Ursulescu A, Nagib R, Shanmuganathan S, Albert M, Reichert S, et al Off-pump versus on-pump redo coronary artery bypass grafting: A propensity score analysis of long-term follow-up. J Thorac Cardiovasc Surg. May 11, 2019 [Epub ahead of print].

20. Schepens M. Type B aortic dissection: new perspectives. J Vis Surg. 2018;4:75.

21. Dake MD, Miller DC, Semba CP, Mitchell RS, Walker PJ, Liddell RP. Transluminal placement of endovascular stent-grafts for the treatment of descending thoracic aortic aneurysms. N Engl J Med. 1994;331:1729-34.

22. Tjaden BL, Sandhu H, Miller C, Gable D, Trimarchi S, Weaver F, et al. Outcomes from the Gore Global registry for endovascular aortic treatment in patients undergoing thoracic endovascular aortic repair for type B dissection. J Vasc Surg. 2018;68:1314-23.

23. Song C, Lu Q, Zhou J, Yu G, Feng X, Zhao Z, et al. The new indication of TEVAR for uncomplicated type B aortic dissection. Medicine (Baltimore). 2016;95: e3919.

24. Elefteriades JA, Lovoulos CJ, Coady MA, Tellides G, Kopf GS, Rizzo JA. Management of descending aortic dissection. Ann Thorac Surg. 1999;67:2002-5.

25. Hagan PG, Nienaber CA, Isselbacher EM, Bruckman D, Karavite DJ, Russman PL, et al. The International registry of acute aortic dissection (IRAD) —new insights into an old disease. JAMA. 2000;283:897-903.

26. Ehrlich MP, Dumfarth J, Schoder M, Gottardi R, Holfeld J, Juraszek A, et al Midterm results after endovascular treatment of acute, complicated type B aortic dissection. Ann Thorac Surg. 2010;90:1444-9.
27. Zeeshan A, Woo EY, Bavaria JE, Fairman RM, Desai ND, Pochettino A, et al Thoracic endovascular aortic repair for acute complicated type B aortic dissection: superiority relative to conventional open surgical and medical therapy. $J$ Thorac Cardiovasc Surg. 2010;140:S109-15.

28. De Rango P, Estrera AL. Uncomplicated type B dissection: are there any indications for early intervention? J Cardiovasc Surg. 2011;52:519-27.

29. Leurs LJ, Bell R, Degrieck Y, Thomas S, Hobo R, Lundbom J, et al Endovascular treatment of thoracic aortic diseases: combined experience from the EUROSTAR and United Kingdom thoracic endograft registries. J Vasc Surg. 2004;40:670-9.

30. Won JY, Suh SH, Ko H, Lee KH, Shim WH, Chang BC, et al. Problems encountered during and after stent-graft treatment of aortic dissection. J Vasc Interv Radiol. 2006;17:271-81

31. Xu SD, Huang FJ, Yang JF, Li ZZ, Wang XY, Zhang ZG, et al. Endovascular repair of acute type B aortic dissection: early and mid-term results. J Vasc Surg. 2006;43:1090-5.

32. Zipfel B, Buz S, Hammerschmidt R, Krabatsch T, Duesterhoeft V, Hetzer R Early clinical experience with the E-vita thoracic stent-graft system: a single center study. J Cardiovasc Surg. 2008;49:417-28.

33. Chemelli-Steingruber I, Chemelli A, Strasak A, Hugl B Hiemetzberger R, Jaschke W, et al. Endovascular repair or medical treat ment of acute type B aortic dissection? A comparison. Eur J Radiol. 2010;73:175-80

34. Iannuzzi JC, Stapleton SM, Bababekov YJ, Chang D, Lancaster RT, Conrad MF, et al. Favorable impact of thoracic endovascular aortic repair on survival of patients with acute uncomplicated type B aortic dissection. J Vasc Surg. 2018; 68:1649-55.

35. Neuhauser B, Greiner A, Jaschke W, Chemelli A, Fraedrich G. Serious complications following endovascular thoracic aortic stent-graft repair for type B dissection. Eur J Cardiothorac Surg. 2008;33:58-63.

Key Words: aortic dissection, endovascular procedures, outcomes 
TABLE E1. Postoperative outcomes of different treatments for the left subclavian artery in the TEVAR group

\begin{tabular}{|c|c|c|c|c|c|}
\hline Variable & Chimney stent & Completely covered & Partially covered & Not covered & $P$ value \\
\hline Number in TEVAR, $\mathrm{n}(\%)$ & $4(2.8)$ & $9(6.2)$ & $35(24.1)$ & 97 (66.9) & \\
\hline All-cause death, $\mathrm{n}(\%)$ & $0(0)$ & $0(0)$ & $2(1.4)$ & $7(4.8)$ & .663 \\
\hline Cumulative events, n (\%) & $1(0.7)$ & $1(0.7)$ & $8(5.5)$ & $13(9.0)$ & .830 \\
\hline
\end{tabular}

Values are $\mathrm{n}(\%)$. The differences were assessed with log-rank test. TEVAR, Thoracic endovascular aortic repair.

TABLE E2. Postoperative outcomes of whether to accept adjunctive stent implantation of visceral branches in the TEVAR group

\begin{tabular}{lccc}
\hline \multicolumn{1}{c}{ Variable } & Received adjunctive stent & Without adjunctive stent & P value \\
\hline $\begin{array}{l}\text { Number of patients in the } \\
\text { TEVAR group, } \mathrm{n}(\%)\end{array}$ & $12(8.3)$ & $133(91.7)$ \\
All-cause death, $\mathrm{n}(\%)$ & $0(0)$ & $9(6.2)$ & .352 \\
Cumulative events, $\mathrm{n}(\%)$ & $2(1.4)$ & $21(14.5)$ & .937 \\
\hline
\end{tabular}

Values are $\mathrm{n}(\%)$. The differences were assessed with log-rank test. TEVAR, Thoracic endovascular aortic repair. 